\title{
Non-Cognitive Factors Influencing Science Achievement in Malaysia and Japan: An Analysis of TIMSS 2015
}

\author{
Lilia Ellany Mohtar ${ }^{1 *}$, Lilia Halim ${ }^{1}$, Mohd. Ali Samsudin ${ }^{2}$, Mohd Erfy Ismail ${ }^{3}$ \\ ${ }^{1}$ Universiti Kebangsaan Malaysia, Faculty of Education, Bangi, Selangor, MALAYSIA \\ 2 Universiti Sains Malaysia, School of Educational Studies, Pulau Pinang, MALAYSIA \\ ${ }^{3}$ Universiti Tun Hussein Onn, Faculty of Technical and Vocational Education, Batu Pahat, Johor, MALAYSIA
}

Received 9 April 2018 - Revised 31 December 2018 - Accepted 4 January 2019

\begin{abstract}
Japan's continual excellent achievement in TIMSS has led to many research and discussions of the Japanese school system as a way of understanding the factors and system that underlie Japan's success in TIMSS. However, comparative studies have focused more on cognitive skills and less on non-cognitive skills as plausible factors for the continual success. Thus, this study aimed to examine the non-cognitive factors related to students' science achievement in TIMSS. This study adopted secondary data analysis where the analysis was carried out on TIMSS 2015 data for respondents from Malaysia and Japan. This study proposed two models for each country which contained five constructs, namely four independent variables which are science teaching practices, victims of bullying, attitude towards science, school climate, and one independent variable i.e. science achievement. From the structural model of multiple group comparison analysis, almost all non-cognitive factors in the model showed significant difference between the two countries except for the relationship between attitude towards science and science achievement in TIMSS.
\end{abstract}

Keywords: science teaching practices, school climate, attitude towards science, victims of bullying, science achievement

\section{INTRODUCTION}

The performance of countries participating in international benchmark tests (e.g., TIMSS) is a major concern among educators and policymakers (Bofah \& Hannula, 2015). The Trends in International Mathematics and Science Study (TIMSS) is the International Association for the Evaluation of Educational Achievement's (IEA) largest comparative study in terms of longitude, participation and number of research populations (Drent, Meelissen \& van der Kleij, 2013; Shi et al., 2016). It is also known as the most widely accepted international assessment of students at the fourth and eighth grade in mathematics and science education (Shi et al., 2016). TIMSS's goal is also to provide countries with information to make 'up-to-date' decisions about how to improve teaching and learning in mathematics and science. Thus, TIMSS serves as a benchmark for many countries including Malaysia, particularly regarding the performance of students in Malaysia in comparison to their counterparts of similar age in terms of thinking processes assessed in TIMSS (Ismail et al., 2017; Martin \& Mullis, 2006).

TIMSS 2015 is the sixth assessment in the TIMSS series that monitors 20 years of trends in educational achievement, together with comprehensive data on students' contexts for learning mathematics and science. Fiftyseven countries and seven bench marking entities (regional jurisdictions of countries such as states or provinces) participated in TIMSS. In total, more than 580,000 students participated in TIMSS 2015. Drent, Meelissen and van der Kleij (2013) argue that TIMSS not only offer the ranking of a country in terms of achievement scores but also provide the teaching and learning context of a country which is measured through questionnaires that the students, the teachers, the school principals and the curriculum experts of each country have to complete. According to Fensham (2008), students are asked about their home, school lives, self-perception and attitudes towards science

(C) 2019 by the authors; licensee Modestum Ltd., UK. This article is an open access article distributed under the terms and conditions of the Creative Commons Attribution License (http://creativecommons.org/licenses/by/4.0/).






\section{Contribution of this paper to the literature}

- We used secondary data analysis to compare four non-cognitive factors that predict science achievement of Malaysia and Japan in TIMSS 2015 data which were drawn from students' questionnaire in TIMSS's 2015 report; these non-cognitive factors are science teaching practices, school climate, attitude towards science and victims of bullying.

- The software called Analysis of Moment Structures (AMOS) was used to simultaneously analyse large-scale assessments such as TIMSS.

- The current study found each of the non-cognitive factors had a different or similar predicting power on students' achievement, which are new findings for the literature on comparative study.

and out of school support. The variables in the students' questionnaire vary from year to year depending on the contemporary issues that might affect students' achievement.

The information from the questionnaires provides an in depth insight into the diverse characteristics of education systems from all over the world that are related to educational outcomes, such as student achievement. In addition, countries which have participated in the TIMSS projects (which is repeated every fourth year) are able to analyse trend data across assessments. Thus, the TIMSS data allow a country to also examine factors that might affect students' achievement based on the teaching and learning context of a country that persistently performs well. According to Drent et al. (2013), most studies that draw upon TIMSS data often conduct comparative study. Comparison is particularly carried out between western and high scoring Asian countries since countries like Japan and Singapore are often at the top of the performance table.

Hence, this study aimed to add to the current literature by comparing the performance of Malaysia and Japan through comparison of the hypothesis model of relevant non-cognitive factors affecting science achievement based on the results of TIMSS 2015. The hypothesis model is tested using the SEM-AMOS (SEM) analysis. This SEM analysis study is generally aimed at improving the achievement of TIMSS but not directly on the achievement score. But the intervention is made on independent variables which are significant predictors for the TIMSS achievement in the context of the SEM model. It is known that SEM-AMOS provides powerful statistical analysis to predict.

Independent variables selected in this study are based on factors that are being collected by the IEA in reviewing the background and learning environment that are related to the TIMSS results. These independent variables (science teaching practices, victims of bullying, attitude towards science, school climate) are important to be tested in relation to TIMSS 2015 results in order to plan suitable and relevant interventions. It is expected that by carrying out such a comparison, better and meaningful understanding of the similarities and differences in the performance of the countries can be gleaned, enabling the countries to learn from each other based on the similarities and differences identified.

\section{BRIEF VIEW OF EDUCATIONAL SYSTEMS}

Malaysia and Japan are countries in the Asian region. Malaysia is a multi-cultural country while Japan is a homogenous country in terms of race, religion and culture.

\section{Educational System in Malaysia}

Primary and secondary schools in Malaysia fall under the responsibility of the Ministry of Education. Malaysia has a centralised curriculum that focuses on developing well-balanced individuals who are knowledgeable, skilful, ethical, and responsible. Malaysia also aims to become a regional centre of excellence in education. Malaysia has been reviewing its educational system as it embraces new innovations in theories of learning, advancement of technology or impact of globalisation (Mullis et al., 2016). In terms of science curriculum, students are to acquire scientific knowledge, the related thinking processes and apply the knowledge and skills in their everyday situation (Ministry of Education Malaysia, 2003). The science curriculum in Malaysia also aims to instil scientific attitudes and noble values so that students develop into balanced individuals who are not only knowledgeable but also become progressive citizens in science and technology with high moral standards (Mullis et al., 2016).

\section{Educational System in Japan}

Japan and Malaysia are similar in their educational administration system in that both countries use a centralised administration system. The Ministry of Education, Culture, Sports, Science and Technology is responsible for all education in Japan (EP-Nuffic, 2015). The national science standards, objectives, and content for primary, lower secondary and upper secondary education is presented in the national curricula, called the Courses of Study. The goal of the curriculum is to keep up with societal changes over the years and the needs of each age 
group (Mullis et al. 2016). The overall objectives for science at the lower secondary level (Grades 7 to 9) comprise the following: enable students to take an active interest in natural things and phenomena and to carry out observations and experiments with a sense of purpose; help students to develop the ability to perform investigations scientifically and to develop a positive attitude about these investigations; help students to deepen their understanding of natural things and phenomena; and help students to develop scientific ways of observing and thinking (Ministry of Education, Culture, Sports, Science and Technology, 2008).

\section{Japan and Malaysia's Achievement in TIMSS}

In TIMSS 2015, a total of 9,726 students (14 years of age) in Malaysia were chosen to sit for the test and Malaysia scored an average of 471 for Science (rank 24) (Ministry of Malaysian Education, 2016). Previously, Malaysia was at its best score of 510 for science, surpassing TIMSS' centre-point scale of 500 points in 2003. However, in 2007, TIMSS' score for Science declined to 471 and continued to drop to 426 in 2011. Malaysian students recorded better results in the 2015 Trends in International Mathematics and Science Study (TIMSS), achieving the highest increase of 45 points among 16 nations that had shown improvements for Science (Ministry of Malaysian Education, 2016).

In comparison, the average scores for science among $8^{\text {th }}$ grade students (14 years of age) in Japan showed that their score is always among the top achievers in TIMSS. In TIMSS 2011, Japan obtained an average score of 570. However, in 2007 and 2011, Japan's TIMSS score for science declined to 554 and 552, respectively. However, in TIMSS 2015, Japan obtained the best average score in science (571) which was ranked second. The results show that Japan continues to dominate international ranking for science. The performance of eighth grade Japanese students is always comparably higher than that of Malaysian students. Many observations, reports, and analyses on Japanese science lessons have been made available in the attempt to understand the context of science education in Japanese classrooms. Linn et al. (2000) observed that Japanese education nurtures respectful discussion in small groups (science lessons) beginning from preschool. All these efforts are aimed towards planning a better model or ideal science programme in schools.

\section{TIMSS-based studies}

A lot of research has reported on factors that might encourage students' learning and achievement. Drent, Meelissen and van der Kleij (2013), for instance, conducted a systematic review on TIMSS-related studies in which science achievement is the dependent variable. However, most of the previous research has focused on data from the western and high-scoring Asian countries such as the USA, Australia and Japan. Studies about factors that affect students' achievement may benefit the students by allowing them to better understand the factors that can affect their academic performance. The education-related parties may be able to improve academic performance by looking at the factors instead of changing the whole system or curriculum in the country. Itoh and Phouttha (2005) assert that educational experts, regardless of developed or developing countries, aim to employ different styles of education programmes. Every country in any part of the world is continuously seeking for the kinds of system or curriculum that would work for their country. Itoh and Phouttha (2005) further argue that non-systemic factors such as the students' surroundings and individual factors might affect their achievement.

Apart from cognitive outcomes, research on students' affective domain and outcomes has gained prominence. Shulman and Tamir (1972) have long argued that affective outcomes are as important as cognitive outcomes in education. She and Fisher (2002) further assert that affective outcome is now being given emphasis in the curricula. Ismail et al. (2017) examined the factors related to student's science achievement among the Malaysian students who participated in TIMSS 2011, namely parental involvement, school discipline and attitude towards science by using secondary data analysis. The researchers found that parental involvement, school disciplinary climate and attitude towards science are the possible factors for student's science achievement. Nevertheless, the tested model showed that there is no relationship between school discipline with attitude towards science and school discipline with science achievement of students, at least for Malaysian students.

Lay and Chandrasegaran (2016) explored the predictive effects of motivation towards learning science on science achievement among Malaysian and Singaporean eighth graders who participated in the TIMSS 2011. The study, which used secondary data analysis, found that the eighth-graders' liking and valuing of learning science were positively associated with Malaysian and Singaporean Grade 8 students' science achievement. Hence, this present study extended the secondary analysis in that the variables examined were different, namely science teaching practices, victims of bullying, attitude towards science, school climate and their effects on science achievement. Additionally, this study also extended the secondary analysis by comparing the Malaysian model to the Japanese model. 


\section{FACTORS PREDICTING SCIENCE ACHIEVEMENT}

Each student who participated in TIMSS 2015 had to complete a Student Questionnaire. The questionnaire asked about aspects and sub aspects of students' home and school live, including basic demographic information, their home environment and educational resources, school climate for learning, school safety including student bullying, attitude towards learning science and classroom instruction including science teaching practices (Martin et al., 2017). Thus, it is impossible to take all aspects or factors reported in the result of TIMSS 2015 to test its correlations on the achievement of TIMSS in one research. So, the researchers have selected four variables (victims of bullying, science teaching practices, attitude towards science and school climate) to test their correlations with the achievement of TIMSS 2015 and then compared the significance and strength of the relationship for the case of Malaysia and Japan simultaneously by using SEM-AMOS analysis.

These four variables were selected based on a model proposed by Scheerens (2008) related to 'Basic system model on the functioning of education'. Studies by Al-Raqqad et al., (2017), Bandura, (1993; 1997), Bietenbeck (2011), Ismail et al. (2017), Reynolds et al. (2017) and Wang and Degol, (2015) stated that all four variables may predict science achievement. The selection of these four factors is also the limitation of the research which is determined by the researcher intentionally but can provide useful information to science education research especially on the effect of non-cognitive factors on achievement at the secondary school level.

\section{Science Teaching Practices}

Bietenbeck (2011) concludes that there is substantial variation in teacher quality and that its impact on student achievement is large. One aspect of teacher quality is teachers' pedagogical content knowledge (PCK) (Halim, Abdullah \& Meerah, 2014). The researchers argued that students expect teachers to have strong content knowledge, effective pedagogical skills and competency in social skills. De Jong (2009) argues that there are basic elements in PCK of a teacher: a) knowledge of students' conceptions of a topic, b) knowledge of effective teaching strategies including explanations, analogies and experiments, and c) strong understanding of subject matter. These basic constituents of PCK among teachers are the most important variable in explaining differences in the students' appreciation of the lessons and the subject being taught at the class level. These kinds of teaching practices are important towards developing students' affective outcomes in education. In this paper, science teaching practices refer to the role of explanation by the teacher in the science class. Effective teaching practices contribute to effective understanding of science lessons.

\section{Victims of Bullying}

Bullying is considered a common form of violence and it is often a part of students' lives in schools, either being the victims of bullying or the bullies themselves. According to Al-Raqqad et al. (2017), bullying comes in many forms such as verbal abuse, physical assaults, threats, jokes or language and criticisms. Bullying leads to the understanding among students that schools are no more a safe place to be in (Maliki et al., 2009). Bullying is deemed as a serious problem in academic settings in all parts of the world and often has negative impact on academic performance. The study by Al-Raqqad et al. (2017) concluded that school bullying has an effect on student's academic achievement, either on the victims or the bullies. When students suffer from bullying, it affects their personality traits and self-confidence, and subsequently affects their academic achievement in core courses such as science and mathematics (Topcu, Erbilgin \& Arikan, 2016). In addition, due to fear of being in school, victims of bullying are unable to follow their lessons as a result of lack of attention or being absent from school since school is no longer a safe place. Moreover, they would miss opportunities to participate in discussions or even to enjoy school activities. Many researchers found that there is a strong relationship between bullying and academic achievement (Topcu, Erbilgin \& Arikan, 2016). Bullied students lose concentration when they are attending their classes (Al-Raqqad et al., 2017).

Martin et al. (2017) wrote in the report of TIMSS 2015 results stating that students who attended schools with unsafe environments had much lower achievement than their friends in orderly schools. Factors being victims of bullying are reported in Martin et al. (2017) and the result shows there is growing evidence that school-related bullying is increasing and does have a negative impact on student achievement (Martin et al., 2017). This shows that a study of bullying is important if teachers or schools want to improve TIMSS results and science achievement. In other words, improvement in science achievement does not only depend on the teaching of mastery of the subject content only but also need to address the disorderly environment such as bullying problems in schools.

\section{Attitude towards Science}

Attitude towards science has direct and indirect influence on achievement and acts as mediators which arouses students' mental capability to achieve success (Mohtar, Halim \& Iksan, 2016). However, many empirical studies 
found that students' attitude towards science have become increasingly negative since the mid-20th century (Alias et al., 2014; Son, 2009). In their study, Ismail et al. (2017) found a negative significant relationship between attitude towards science and science achievement in TIMSS Malaysia. Their results showed that students' attitude toward science was high, but student achievement was otherwise. According to Ismail et al. (2017), students claimed they enjoy learning science, learn many interesting things in science and are interested in science. However, interest in science did not lead to a high score in TIMSS 2011 science test. Ismail et al. (2017) concluded that the attitude of students towards science does not reflect the real achievement of science because of the examination-oriented education system in Malaysia where science achievement is measured through pen and paper type of examination. Nevertheless, a lot of research has shown that attitude towards science may influence science achievement (Pehlivan \& Koseoglu, 2011; Veloo et al., 2015).

Normally, students who will sit for TIMSS will definitely be under pressure and thus students may have negative attitude towards science and thus may have negative influence on their science achievement. As shown by Ismail et al. $(2017 ; 2018)$ the Malaysian students who sat for TIMSS in 2011 showed a negative correlation with science achievement. However, according to Osborne et al. (2003), the attitude towards science that has formed will remain and difficult to change. This is because the attitude of student has been reinforced by other factors throughout the learning process such as environment, learning approach and interest (Shulman, 2013). Thus, it can be argued that one's attitudes towards science may or may not be the result as being under pressured in performing well in TIMSS. This study is to identify to what extent students' attitudes towards science has a significant effect on the achievement in science or otherwise.

\section{School Climate}

School climate refers to the quality and traits of school life (Cohen et al., 2009). School climate is often assumed to be the most important factor that is able to explain various factors related to student achievement such as reducing problematic behaviours and dropout rates (Maxwell et al., 2017; Wang \& Degol, 2015). The most cited theory to explain the role of school climate in student achievement is social cognitive theory (Bandura, 1993, 1997). The theory suggests that school climate which gives emphasis to promoting high academic achievement, providing supportive teacher-student relationships, and creating emotionally and physically safe environment will have a positive impact on the students' development including their academic achievement. Social cognitive theory is also frequently applied to school climate research when examining the achievement goal structure. Goal structure is a prime example of how schools can model and instil motivational beliefs in their students, thereby influencing their academic achievement (Wang \& Degol, 2015). The study carried out by Topcu, Erbilgin and Arikan (2016) showed that Korean students who reported that they liked school, felt safe, and felt they belonged to the school were more successful in science and mathematics. In TIMSS' 2015 questionnaire, school climate refers to the students' sense of belonging. Students' sense of belonging might affect their academic performance. If the school climate is positive and supportive, and this, in turn, facilitates the student to identify with the school as a salient group, then the student is more likely to reflect and embed the school values and norms, focusing on learning and achievement, with their behaviour (Reynolds et al., 2017).

\section{Issues}

Teaching and learning cultures in each country are different. Although good PCK is important for effective science teaching, achievement in TIMSS is also determined by the teaching of science content. Science content is also the most important component of PCK other than general pedagogy. Unlike in western countries, science teachers in Japan focus less on pure scientific aspects; they tend to conduct science education with the aim of building an industrialised and modernised society (Kawasaki, 1996). In other words, science education in Japan focuses on practicing science for industrial development and technical innovation. This teaching and learning culture connects science with students' everyday lives and flows into their ordinary life through technology which helps a lot in students' thinking and leads to achievement in TIMSS (Kawasaki, 1996). In contrast, in countries like Malaysia, the teaching and learning culture is an exam-oriented one with emphasis on test questions that require low order thinking skills to the effect that the students are unable to answer high-level thinking skills questions in TIMSS (Ibrahim, 2015).

In Malaysia, developing values such as attitude towards science is an objective in secondary school science education (Ministry of Education Malaysia, 2005; Mullis et al., 2016) and the study by Ismail et al. (2017) shows that attitude towards science among Malaysian students in TIMSS 2011 was high. However, comparison between the results of the Japanese and international average showed that Japanese students' attitude towards science scored one of the lowest percentages in the world (Suzuki, 2007). According to the Ministry of Education, Culture, Sports, Science and Technology, this is because Japanese students believe it is not necessary to like their studies, and this is why many students do not have positive attitude towards science subject in school (Suzuki, 2007). Among other 


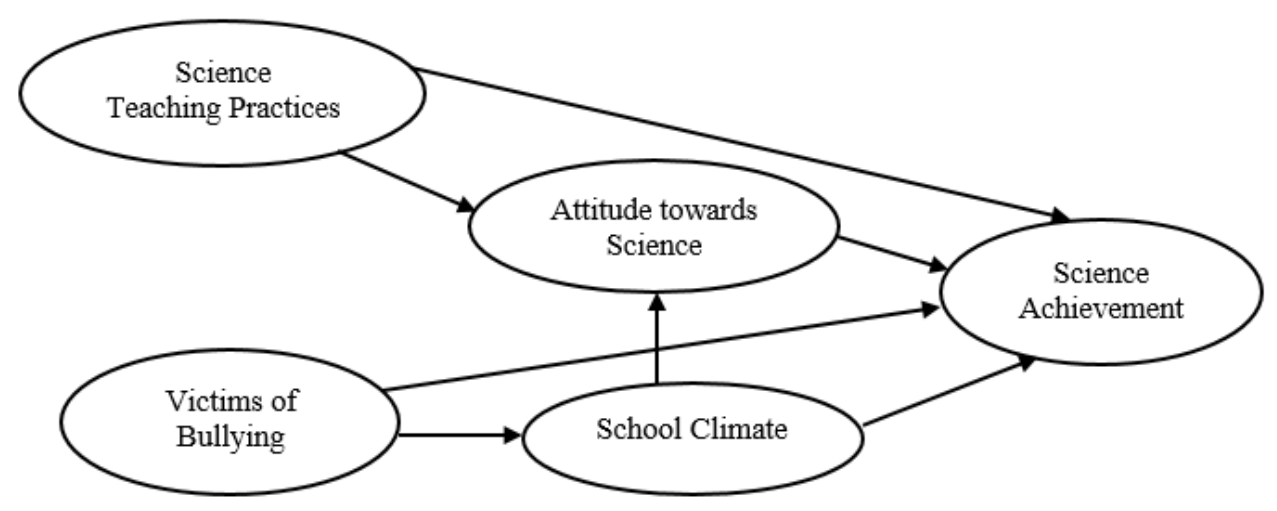

Figure 1. Conceptual Framework

things reported in the TIMSS result is bullying. In TIMSS 2015, 80\% of the Japanese students said they were never bullied compared to Malaysia where $48 \%$ of the students reported to have never been bullied. However, according to the Ministry in Japan, some 224,540 reports of school bullying emerged in 2015-2016 in Japan and that it was a 19 per cent increase from the previous year (Megumi, 2017). Another aspect reported in TIMSS is school climate which asked for students' view of their school. Few studies have been conducted in Japan on the sense of belonging, including sense of belonging to school (Togari et al., 2011). However, in TIMSS 2015, Malaysia (46\%) scored a higher percentage of student's having a high sense of belonging to school compared to Japan $(27 \%)$.

\section{CONCEPTUAL FRAMEWORK}

Figure 1 shows the conceptual framework of this present study. Overall, there are five research variables. In this conceptual framework, four factors that influence science achievement in TIMSS 2015 or in this study labelled 'science achievement' were examined. These four factors are students' view of their science teachers' teaching practices (science teaching practices), students' view of themselves as victims of bullying, students' view of the school (school climate) and students' attitude towards science. The positive directional relationship between the four variables and science achievement and among the variables is based on 'Basic system model on the functioning of education' (Scheerens, 2008) and is supported by literature review (Al-Raqqad et al., 2017; Bandura, 1993; 1997; Bietenbeck, 2011; Ismail et al., 2017; Reynolds et al., 2017; Wang \& Degol, 2015).

According to Scheerens (2008), the 'Basic system model on the functioning of education' has a multilevel structure, which means that the model includes input factors such as teacher characteristics which are assumed to be related to outputs such as student achievement through process factors. Process factors are part of the so-called 'black box' in which teaching and learning take place and in which inputs are transformed into outputs. Process factors can be divided into factors at the school level (e.g., school climate) and factors from student characteristics (e.g., attitude) (Drent, Meelissen \& van der Kleij, 2013; Scheerens, 2008). In addition, Scheerens (2008) also assumed that the relation of input and process factors with student achievement is moderated by contextual factors which may refer to a country or school characteristics (Scheerens, 2008). Thus, based on the model, two countries were selected to be studied, namely Malaysia and Japan. It is important to advance the country as the moderation in the model of science achievement in TIMSS as the moderating effect addresses a specific variable that is the strongest predictor of science achievement in the proposed model.

\section{HYPOTHESIS MODEL}

Based on the conceptual framework, a structural model was constructed using AMOS software. The structural model of factors that affect science achievement is shown in Figure 2. Based on Figure 2, five latent variables were of particular interest in this study: (i) science teaching practices, (ii) attitude towards science, (iii) victims of bullying, (iv) school climate and (v) science achievement. All five constructs are represented by three indicators. The four constructs that influence science achievement (science teaching practices, bullying, attitude towards science, school climate) are represented by three items selected from the questionnaire. Each item used a different categorical Likert-type scale based upon item format and labelled with a code as in the book 'Supplement 1: International Version of the TIMSS 2015 Context Questionnaires TIMSS 2015 User Guide for the International Database' (IEA, 2017). The variable of student achievement in science was taken from the student scores in the science test that measures three cognitive components, namely knowing, applying and reasoning. 


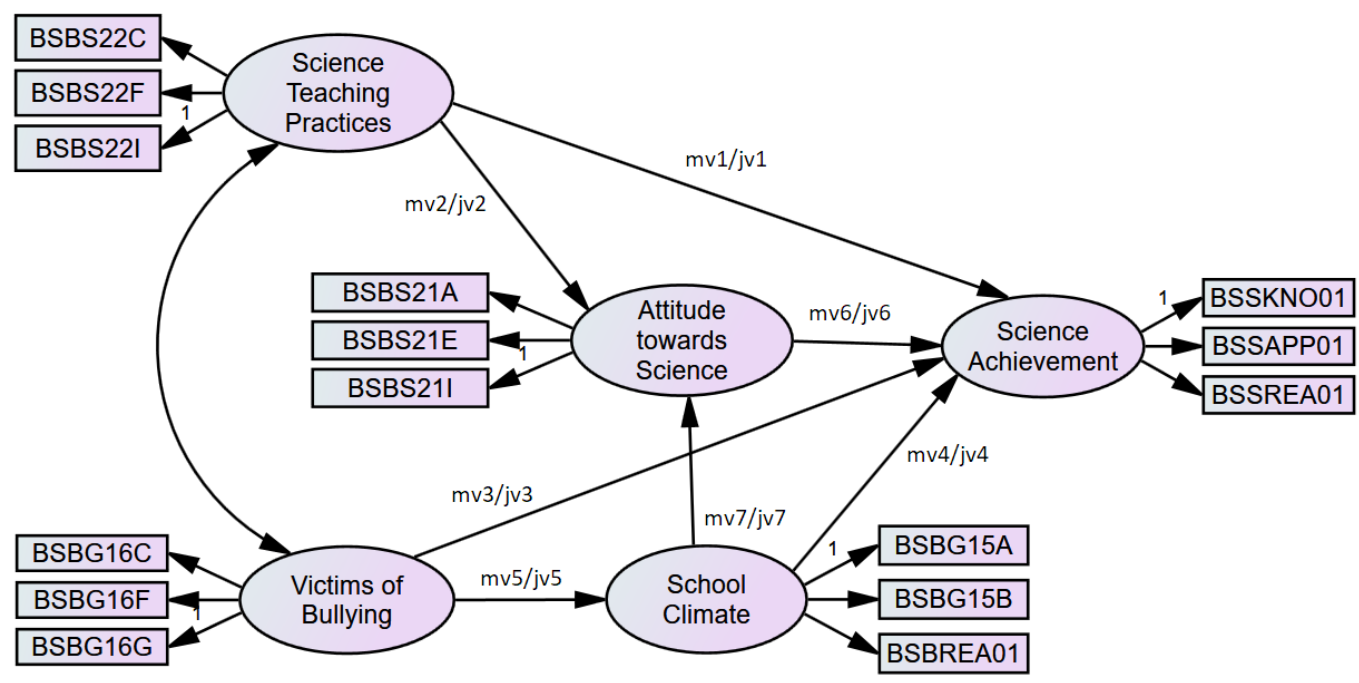

Figure 2. Structural Model in AMOS graphic

Objective of the study: The research was conducted to identify model fit for the hypothesised model and causal directional effect between the five variables as shown in Figure 2 for each country (statistically significant at pvalue <0.05). Importantly, the research aimed to assess whether the structural model varies as a function of countries (significant at critical ratio, $C R< \pm 1.96, p>0.05$ ). For this purpose, the analysis method employed is multiple group comparison via structural equation modelling. It was hypothesised that the moderating effect of country on the structural model's construct relationship is significant. Each hypothesis can be seen on each path and labelled with ' $m v^{\prime}$ for Malaysia and ' $\mathrm{jv}$ ' for Japan. Failure to support this hypothesis means that both countries do not moderate the structural model of science achievement. This research finding is important for the practical implication of the science achievement model (Figure 2).

Country moderation hypothesis: The conceptual model suggests that the structural model of science achievement is significantly different between countries. Therefore, this research posited the following hypothesis:

$\mathrm{H}_{1}$ : Country moderates the causal dependence relationship between science achievement and science teaching practices

$\mathrm{H}_{2}$ : Country moderates the causal dependence relationship between attitude towards science and science teaching practices

$\mathrm{H}_{3}$ : Country moderates the causal dependence relationship between science achievement and victims of bullying

$\mathrm{H}_{4}$ : Country moderates the causal dependence relationship between science achievement and school climate

$\mathrm{H}_{5}$ : Country moderates the causal dependence relationship between school climate and victims of bullying

$\mathrm{H}_{6}$ : Country moderates the causal dependence relationship between science achievement and attitude towards science

$\mathrm{H}_{7}$ : Country moderates the causal dependence relationship between school climate and attitude towards science.

\section{METHODOLOGY}

This study was conducted through secondary data analysis using the TIMSS 2015 data. At a time when vast amounts of data are being gathered and documented by researchers all over the world, the practicality of utilising existing data for research is becoming more prevalent (Johnston, 2014). Secondary data analysis is an analysis of data that was collected by someone else for another primary purpose. TIMSS data is considered as a secondary data set. The secondary data set is usually a large data set that typically covers a broad sample of individuals and is generally representative of some broader population. As TIMSS data is a secondary data set, it becomes part of the public domain. Major science education policy initiatives or reforms around the world are more likely derived from TIMSS result. Moreover, TIMSS data is one of the most widely discussed and used international assessments. International Association for the Evaluation of Educational Achievement (IEA) is the organisation that manages online repositories which allow easy access and serve to help with downloading of databases and documentation. 
Table 1. Code and Item for each Construct

\begin{tabular}{|c|c|c|}
\hline Construct & Code & Item \\
\hline \multirow{3}{*}{$\begin{array}{l}\text { School Climate } \\
\text { Students' View of the School } \\
\text { (What do you think about your school? Tell us how much you agree with } \\
\text { these statements.) }\end{array}$} & BSBG15A & I like being in school \\
\hline & BSBG15B & I feel safe when I am at school \\
\hline & BSBG15F & I am proud to go to this school \\
\hline \multirow{3}{*}{$\begin{array}{l}\text { Victims of Bullying } \\
\text { Students' View of Themselves as Victims of Bullying } \\
\text { (During this school year, how often have other students from your school } \\
\text { done any of the following things to you } \\
\text { (including through texting or the Internet))? }\end{array}$} & BSBG16C & Spread lies about me \\
\hline & BSBG16F & $\begin{array}{l}\text { Made me do things I didn't } \\
\text { want to do }\end{array}$ \\
\hline & BSBG16G & $\begin{array}{l}\text { Shared embarrassing information about } \\
\text { me }\end{array}$ \\
\hline \multirow{3}{*}{$\begin{array}{l}\text { Science Teaching Practices } \\
\text { Students' View of Science Teachers' Teaching Practices } \\
\text { (How much do you agree with these statements about your science } \\
\text { lessons?) }\end{array}$} & BSBS22C & $\begin{array}{l}\text { I am interested in what my } \\
\text { teacher says }\end{array}$ \\
\hline & BSBS22F & My teacher is good at explaining science \\
\hline & BSBS22I & $\begin{array}{l}\text { My teacher tells me how to do } \\
\text { better when I make a mistake }\end{array}$ \\
\hline \multirow{3}{*}{$\begin{array}{l}\text { Attitude towards Science } \\
\text { Students' Attitude towards Science } \\
\text { (How much do you agree with these statements about learning science?) }\end{array}$} & BSBS21A & I enjoy learning science \\
\hline & BSBS21E & I like science \\
\hline & BSBS21I & $\begin{array}{l}\text { Science is one of my } \\
\text { favourite subjects }\end{array}$ \\
\hline \multirow{3}{*}{ Science Achievement } & BSSKNO01 & Score \\
\hline & BSSAPP01 & Score \\
\hline & BSSREA01 & Score \\
\hline
\end{tabular}

IEA is recognised as one of the pioneers in the field of international comparison assessments of educational achievement.

The data was analysed by using structural equation modelling (SEM) on the student questionnaire and student achievement scores in science as revealed by TIMSS 2015 data in Malaysia and Japan. The moderation intervention on the structural model's construct relationship between Malaysia and Japan employed multiple group model comparison technique. The reason for using SEM is that it enables researchers to match theories with the data, to decide on the extent to which they fit each other, to test the hypothesised model and to compare the relationship between one variable with other variables simultaneously (Byrne, 2001) between these two countries.

\section{Subjects}

The population of the study consisted of eight graders in Malaysia and Japan The total sample contained 14, 471 students who participated in TIMSS 2015; 9,726 were those randomly selected among Malaysian school students and another 4,745 among Japanese school students. The sample was chosen through a stratified two-stage sampling (Foy \& Joncas, 2000). The first stage involved the selection of schools using random sampling of all the secondary schools in Malaysia and Japan. In the second stage, a single classroom of eighth grade (14 years old) pupils was selected at random for each selected school. Students from these selected classes were asked to complete the students' questionnaires. Details of the sampling procedure, background information of the students and schools, as well as science questions and achievement can be found in TIMSS 2015 reports (Mullis et al., 2015).

\section{Instruments/ Source of Data}

The data used in this study was generated from TIMSS's most recent database. The information was collected from Malaysia and Japan's eight graders in 2015. Table 1 shows the codes and items that were selected from the TIMSS 2015 questionnaire to be reviewed in this study.

\section{Analysis}

Data analysis was based on the SEM approach to test the hypothesised model (Ismail et. al., 2015). For maximum likelihood estimation, a set of goodness-of-fit index was used to evaluate model fit: chi-square $\left(\mathrm{c}^{2}\right)$, root mean square error of approximation (RMSEA), comparative fit index (CFI) and Tucker-Lewis index (TLI). Additionally, Akaike information criterion (AIC) and Bayesian information criterion (BIC) were used to help compare the models (Loehlin, 2004). Small values on AIC and BIC suggest better models in terms of model fit and parsimony. The significant $p$-value was used to explain the causal directional relationship of each model for Japan and Malaysia separately. Then, the critical ratio test was employed to check for country differences in the path coefficient. All analyses were performed using AMOS18. 
EURASIA J Math Sci and Tech Ed

Table 2. Chi-square Goodness of Fit, Baseline Comparison Fit Indices and RMSEA for Group Invariant and Group Variant

\begin{tabular}{|c|c|c|c|c|c|}
\hline \multicolumn{6}{|c|}{ CMIN } \\
\hline Model & NPAR & CMIN & DF & $\mathbf{P}$ & CMIN/DF \\
\hline Invariant Model & 94 & 4898.479 & 176 & .000 & 27.832 \\
\hline Variant Model & 101 & 4672.061 & 169 & .000 & 27.645 \\
\hline Saturated model & 270 & .000 & 0 & & \\
\hline Independence model & 30 & 141733.941 & 240 & .000 & 590.558 \\
\hline \multicolumn{6}{|c|}{ Baseline Comparisons } \\
\hline Model & $\begin{array}{c}\text { NFI } \\
\text { Delta1 }\end{array}$ & $\begin{array}{c}\text { RFI } \\
\text { rho1 }\end{array}$ & $\begin{array}{c}\text { IFI } \\
\text { Delta2 }\end{array}$ & $\begin{array}{c}\text { TLI } \\
\text { rho2 }\end{array}$ & CFI \\
\hline Invariant Model & .965 & .953 & .967 & .954 & .967 \\
\hline Variant Model & .967 & .953 & .968 & .955 & .968 \\
\hline Saturated model & 1.000 & & 1.000 & & 1.000 \\
\hline Independence model & .000 & .000 & .000 & .000 & .000 \\
\hline \multicolumn{6}{|c|}{ RMSEA } \\
\hline Model & & & LO 90 & HI 90 & PCLOSE \\
\hline Invariant Model & & & .042 & .044 & 1.000 \\
\hline Variant Model & & & .042 & .044 & 1.000 \\
\hline Independence model & & & .201 & .203 & .000 \\
\hline
\end{tabular}

Table 3. Akaike Information Criterion and Nested Model Comparisons Statistics

\begin{tabular}{lccccccc}
\hline \multicolumn{7}{c}{ Nested Model Comparisons Assuming Model Group Variant to be Correct } \\
\hline Model & DF & CMIN & P & $\begin{array}{c}\text { NFI } \\
\text { Delta-1 }\end{array}$ & $\begin{array}{c}\text { IFI } \\
\text { Delta-2 }\end{array}$ & $\begin{array}{c}\text { RFI } \\
\text { rho-1 }\end{array}$ & $\begin{array}{c}\text { TLI } \\
\text { rho2 }\end{array}$ \\
\hline Invariant Model & 7 & 226.418 & .000 & .002 & .002 & .000 & .000 \\
\hline
\end{tabular}

\section{RESULTS}

In the output for structural model of multiple group comparisons, there are two data sets: Malaysian students and Japanese students. The result is important to answer whether the proposed science achievement structural model is significantly different between students in Malaysia and Japan. Based on the differences or similarities identified, one could also learn how and what to address in relation to the non-cognitive factors contribution towards or influence on the enhancement of science achievement for both countries.

\section{Measurement Model Analysis of Group Invariant and Group Variant Findings}

For this multi-group analysis, the measurement models for the individual latent constructs and for the constructs taken in pairs across variable were estimated using the data from the sample of Malaysia and Japan There were two data sets in this analysis, each containing 15 measurement variables. Two covariance matrices generated from the two data sets contained 270 sample moments. For the group invariant model, there were 794 parameters to be estimated. Therefore, it had $176(270-94)$ degrees of freedom and yielded a significant chi-square value, $(\mathrm{N}=4898.479, \mathrm{df}=176)=4898.479, \mathrm{p}<0.05$ (Table 2). For the measurement model variant, there were 101 parameters to be estimated. This model, therefore, had 169 (270-101) degrees of freedom, and yielded a significant chi-square value, $\chi^{2}(\mathrm{~N}=4672.061, \mathrm{df}=169)=4672.061, \mathrm{p}<0.05$ (Table 2). Table 2 also shows the baseline comparison fit indices of NFI, RFI, IFI, TLI, and CFI for both models which were above 0.90 (range: $0.974-0.982$ ). The RMSEA values for both group-invariant and group-variant path models were 0.035 and 0.037 , respectively. RMSEA values below 0.08 are considered acceptable (Hair et. al., 2013). These values suggested that the fit of these two models was adequate.

The fit of the two models can also be compared using the AIC measures (Akaike, 1981, 1987). In evaluating the hypothesised model, this measure takes into account both model parsimony and model fit. Simple models that fit well received low scores, whereas poorly fitting models obtained high scores. Table 3 shows the AIC criterion and Nested model comparison statistics. The result of Nested model comparison was also supported by the AIC measures. Table 4 shows the AIC output. The AIC measures for the group-variant model (4874.061) was lower than that for the group invariant model (5086.479), indicating that the group variant model was both more parsimonious and better fitting than the group invariant model. On the basis of the model comparison findings, and assuming that the group-variant model was correct, the group-variant model's estimates were deemed preferable over the group-invariant model's estimates. 
Table 4. Akaike Information Criterion (AIC) output

\begin{tabular}{ccc}
\hline Model & AIC & BCC \\
\hline Invariant Model & 5086.479 & 5086.956 \\
\hline Variant Model & 4874.061 & 4874.573 \\
\hline Saturated model & 540.000 & 541.369 \\
\hline Independence model & 141793.941 & 141794.093 \\
\hline
\end{tabular}

Table 5. Scalar Estimates of Variant Model (Malaysia)

\begin{tabular}{cccccccc}
\hline & Path & & Estimate & S.E. & C.R. & P & Label \\
\hline School_Climate & $<---$ & Victims_Bullying & -.222 & .012 & -18.329 & ${ }^{* *}$ & $\mathrm{mv} 5$ \\
\hline Attitude_Science & $<---$ & Science_Teaching & .652 & .010 & 63.445 & ${ }^{* * *}$ & $\mathrm{mv} 2$ \\
\hline Attitude_Science & $<---$ & School_Climate & .128 & .012 & 10.342 & $* * *$ & $\mathrm{mv} 7$ \\
\hline Science_Achievement & $<---$ & Attitude_Science & -38.738 & 3.320 & -11.669 & ${ }^{* * *}$ & $\mathrm{mv} 6$ \\
\hline Science_Achievement & $<---$ & School_Climate & 18.139 & 2.969 & 6.110 & $* * *$ & $\mathrm{mv} 4$ \\
\hline Science_Achievement & $<---$ & Science_Teaching & -22.580 & 3.135 & -7.202 & ${ }^{* * *}$ & $\mathrm{mv} 1$ \\
\hline Science_Achievement & $<---$ & Victims_Bullying & 28.137 & 2.457 & 11.450 & ${ }^{* * *}$ & $\mathrm{mv} 3$ \\
\hline
\end{tabular}

Table 6. Scalar Estimates of Variant Model (Japan)

\begin{tabular}{cccccccc}
\hline & Path & & Estimate & S.E. & C.R. & P & Label \\
\hline School_Climate & $<---$ & Victims_Bullying & -.368 & .027 & -13.840 & $\star \star \star$ & jv5 \\
\hline Attitude_Science & $<---$ & Science_Teaching & .613 & .015 & 39.932 & $* \star *$ & jv2 \\
\hline Attitude_Science & $<---$ & School_Climate & .056 & .017 & 3.264 & .001 & jv7 \\
\hline Science_Achievement & $<---$ & Attitude_Science & -31.804 & 1.780 & -17.863 & $\star \star \star$ & jv6 \\
\hline Science_Achievement & $<---$ & School_Climate & -.106 & 1.834 & -.058 & .954 & jv4 \\
\hline Science_Achievement & $<---$ & Science_Teaching & -.457 & 1.877 & -.243 & .808 & jv1 \\
\hline Science_Achievement & $<---$ & Victims_Bullying & 2.211 & 2.574 & .859 & .390 & jv3 \\
\hline
\end{tabular}

Table 7. Standardised regression weight of variant model for Malaysia and Japan

\begin{tabular}{ccccccc} 
& \multirow{2}{*}{ Path } & & \multicolumn{3}{c}{ Malaysia } & \multicolumn{2}{c}{ Japan } & \multirow{2}{*}{ Differences } \\
\cline { 3 - 6 } & & & Label & \multicolumn{2}{c}{ Estimate, $\boldsymbol{\beta}$} & .001 \\
\hline School_Climate & $<---$ & Victims_Bullying & $\mathrm{mv} / \mathrm{jv} 5$ & -.281 & -.282 & .098 \\
\hline Attitude_Science & $<---$ & Science_Teaching & $\mathrm{mv} / \mathrm{jv} 2$ & .707 & .609 & .059 \\
\hline Attitude_Science & $<---$ & School_Climate & $\mathrm{mv} / \mathrm{jv} 7$ & .105 & .046 & non-sig. \\
\hline Achievement_Science & $<---$ & Attitude_Science & $\mathrm{mv} / \mathrm{jv} 6$ & -.199 & -.350 & .076 \\
\hline Achievement_Science & $<---$ & School_Climate & $\mathrm{mv} / \mathrm{jv} 4$ & .077 & -.001 & .121 \\
\hline Achievement_Science & $<---$ & Science_Teaching & $\mathrm{mv} / \mathrm{jv} 1$ & -.126 & -.005 & .135 \\
\hline Achievement_Science & $<---$ & Victims_Bullying & $\mathrm{mv} / \mathrm{jv} 3$ & .150 & .015 & \\
\hline
\end{tabular}

Before testing for country differences in the path model, each country was tested separately to see the significance in all seven links by using the p-value. Table 5 shows the scalar estimate of variant model for Malaysia while Table 6 shows the scalar estimate of variant model for Japan. It was found that all coefficients associated with the paths linking exogenous and endogenous variables for the Malaysian respondents were significant based on the $p$-value $(p<0.01)$. However, there were three links that showed negative relationships: victims of bullying to school climate, attitude towards science to achievement in TIMSS science and science teaching to achievement in TIMSS science. For the Japanese respondents, out of the seven coefficients associated with the paths linking exogenous and endogenous variables, four were significant based on the $p$-value $(p<0.05)$. The three non-significant coefficients for Japan were associated with the paths that linked from school climate to achievement in TIMSS science, science teaching to achievement in TIMSS science and victims of bullying to achievement in TIMSS science.

There were four paths that showed negative relationships: victims of bullying to school climate, attitude towards science to achievement in TIMSS science, school climate to achievement in TIMSS science and science teaching to achievement in TIMSS science. This analysis provided important coefficient, namely standardised regression weight or estimate, $\beta$ of variant model for Malaysia and Japan. This coefficient was used to determine the causal direction, either negative or positive, and the strength of the relationship for each country. The causal direction and strength are explained to support the results of critical ratio test. The $\beta$ of variant model for Malaysia and Japan is presented in Table 7.

In order to test for country differences in the path model, it was necessary to firstly, set up separate but identical path models for Malaysia and Japan's samples. Based on AIC measurement, variant measurement model was scrutinised because regression weights from the invariant group measurement model were set to equality; 
Table 8. Critical ratios for differences between parameters (variant model)

\begin{tabular}{cccccccc}
\hline Path & $\mathbf{m v 2}$ & $\mathbf{m v 6}$ & $\mathbf{m v 5}$ & $\mathbf{m v 7}$ & $\mathbf{m v 4}$ & $\mathbf{m v 1}$ & $\mathbf{m v 3}$ \\
\hline jv2 & -2.237 & 11.854 & 42.705 & 24.689 & -5.904 & 7.398 & -11.201 \\
\hline jv6 & -18.232 & 1.845 & -17.738 & -17.935 & -14.428 & -2.559 & -19.753 \\
\hline jv5 & -35.771 & 11.558 & -5.036 & -16.990 & -6.235 & 7.085 & -11.600 \\
\hline jv7 & -29.767 & 11.686 & 13.240 & -3.405 & -6.091 & 7.220 & -11.427 \\
\hline jv4 & -.413 & 10.185 & .063 & -.128 & -5.228 & 6.187 \\
\hline jv1 & -.590 & 10.038 & -.125 & -.312 & -5.294 & 6.054 \\
\hline jv3 & .606 & 9.748 & .945 & .809 & -4.054 & -9.210 & 6.111 \\
\hline
\end{tabular}

therefore, it cannot be the basis to compare country differences. Critical ratio (CR) test was carried out on the regression weights obtained from the variant group measurement model to point out which measured variables were different for Malaysia and Japan's data. The result of CR is shown in Table 8.

Based on Table 8, out of the seven pairwise comparisons between the paths linking exogenous and endogenous variables for Malaysia and Japan, six were found to be significant based on the critical ratio test, $(C R> \pm 1.96, p<0.05)$ and only one link was not significant i.e., the path linking attitude towards science to achievement in TIMSS science (mv6 and jv 6). Briefly, the significant differences on the path coefficient were found between:

(i) mv2 and jv2 (science teaching practices and attitude towards science)

(ii) mv5 and jv5 (victims of bullying and school climate)

(iii)mv7 and jv7 (school climate and attitude towards science)

(iv) mv4 and jv4 (school climate and achievement in TIMSS science)

(v) mv3 and jv3 (victims of bullying and achievement in TIMSS science)

(vi)mv1 and jv1 (science teaching practices and achievement in TIMSS science)

The coefficients of standardised regression weights (estimate, $\beta$ ) were used to compare the direction and strength between the significant paths for both countries. Table 7 shows the comparison of $\beta$-value between Malaysia and Japan. Based on Table 7, out of the six significant paths, only one link showed that Japan demonstrated a negative significantly stronger path coefficient, i.e. victims of bullying to school climate (v5: Japan: $\beta=-.282$, Malaysia: $\beta=-.281$ ) because the estimate, $\beta$ score for Japan was significantly higher than Malaysia's. However, Malaysia demonstrated a negative significantly stronger path coefficient in one link, i.e. science teaching practices to achievement in TIMSS science (v1: Malaysia: $\beta=-.126$; Japan: $\beta=-.005)$. In contrast, other paths showed a positive significantly stronger path coefficient, i.e. science teaching practices and attitude towards science (v2: Malaysia: $\beta=.707$; Japan: $\beta=.609$ ), school climate and attitude towards science (v7: Malaysia: $\beta=.105$; Japan: $\beta=$ .046), school climate and achievement in TIMSS science (v4: Malaysia: $\beta=.077$; Japan: $\beta=.001$ ), and victims of bullying and achievement in TIMSS science (v3: Malaysia: $\beta=.150$; Japan: $\beta=.051$ ). As a conclusion, six hypotheses were accepted, namely $\mathrm{H}_{1}, \mathrm{H}_{2}, \mathrm{H}_{3}, \mathrm{H}_{4}, \mathrm{H}_{5}$ and $\mathrm{H}_{7}$ while $\mathrm{H}_{6}$ was rejected because it was found to be non-significant based on CR. All significant paths were also explained based on the direction and strength.

\section{DISCUSSION}

This research aimed to assess whether the structural model varies as a function of country. Thus, the discussion on significant and directional relationships is based on the result of critical ratio (CR) test employed to check for country differences in the path coefficient.

Based on the structural model comparisons between Malaysia and Japan, it was found that Malaysia demonstrated significantly stronger path coefficient between science teaching practices and achievement in TIMSS science (mv1); however, the relationship was negative. In this research, students' view of science teachers' teaching practices was assessed based on whether: a) students showed interest in what the teacher says, b) teacher is good at explaining science and c) teacher helps to improve their mistakes. However, the results showed that these indicators were found to contribute negatively to science achievement in TIMSS 2015. Most students admitted that their teachers are good in teaching and willing to facilitate the learning process, but such practices were not able to lead the students towards achieving high score in the TIMSS 2015 science test. In addition to the multiple-choice format questions, TIMSS science questions were also posed in the free-response format which required the students to generate and write their own answers or show their work. These questions require students to understand simple and complex information, theorise, analyse, solve problems, use tools, understand routine procedures, science processes and investigate the natural world (IES, 2017).

Consequently, the results of the negative relationship imply that Malaysian teachers need to change their teaching practices towards teaching problem solving routine, giving explanation that promotes higher order thinking skills and minimise 'spoon-feeding' in order to prepare students for such an assessment. The quality of 
science education depends on the quality of instruction that students receive (Prokop et al., 2011). Malaysian science teachers appear the need to improve their PCK namely on how to transform science content for the students' understanding (Halim \& Meerah 2002). PCK in terms of assessing students' understanding and using the information to improve students' understanding appear to be lacking among the Malaysian science teachers. Halim, Abdullah and Meerah (2014) study shows that student need teachers to show them how to overcome their mistakes more effectively. In addition, in this twenty-first century teaching and learning era, teachers need to master more than basic elements in PCK as stated by De Jong (2009). According to Anderman, Sinatra, and Gray (2012), teachers in the twenty-first century should be capable of having PCK such as adaptability (critical scientific thinking and reasoning) skills, complex communication (about abstract concepts, clearly and efficiently) skills and non-routine problem-solving skills (creativity, metacognitively monitor and self-regulate relevant skills and strategies). These skills are required to enable the science teachers to promote students' problem solving skills in science that require creativity and complex cognition which are needed in standardised tests like TIMSS. In the case of Japan, the path between science teaching practices and achievement in TIMSS science (jv1) was also negative but not significant (Table 6). One usually does not interpret such a statistical finding; however, such a finding may provide practical implications. In particular, the common view is that the classroom practices in Japanese schools may provide evidence as to why they score highly in TIMSS, and this should be investigated.

On the other hand, this study found that there was a significantly positive relationship between science teaching practices and attitude towards science (mv2) in favour of Malaysian students. Such teaching practices appear to be liked by students and thus provided positive impact in their perception towards science subject and learning science. In this study, the indicators of attitude towards science were based on liking science, enjoying learning science and preferring science as a favourite subject. One interpretation is that students find the science teaching practices espoused by the teachers are suitable for them. Thus, if science teaching practices are to change from explanation type to problem solving type, it may lead to changes in students' attitudes towards science from positive to negative. Thus, if science practices are to be changed, then it has to be carried out gradually. On the other hand, in the case of Japan, it appears that the science teaching practices there has led to positive scientific attitude towards science which should be encouraged further. Sheldrake, Mujtaba and Reiss (2017) suggest that teaching practices such as interaction, debating, practical or hands-on activities, argumentation approaches and context-based approaches may foster students liking of science subject and enjoyment of learning science. Both Malaysia and Japan have emphasised on students acquiring knowledge in science and technology in the context of natural phenomena and everyday life experiences while practical or hands-on activities are performed by the students every week (Ministry of Education Malaysia, 2005; Ministry of Education, Culture, Sports, Science and Technology, 2008).

The tested model also showed that there was a significant positive relationship between (i) school climate and attitude towards science (mv7) and between (ii) school climate and achievement in TIMSS science (mv4) in favour of Malaysian students. In this study, the indicators of school climate are: like being in school, feel safe at school, and proud to go to school. In sum, students' sense of belonging, feeling safe and proud to go to school were found to be contributing to students' positive attitude towards science and science achievement in TIMSS 2015. Theoretically, these findings are in line with 'Basic system model on the functioning of education' by Scheerens (2008) used as the theoretical framework in this study and in line with the study conducted by Drent, Meelissen and van der Kleij (2013). In their conclusion, Drent, Meelissen and van der Kleij surmised that a safe school with few or no disturbing incidents seems to be positively related to achievement in different contexts (moderator) and this study demonstrated that it is significant in the Malaysian context. Moreover, Sekamany et al. (2016) suggested that positive, safe and well-functioning school is not only necessary for learning, it also attends to safety and teaches socially appropriate attitude among students. Kamaruddin (2006) in a simple survey found that $70 \%$ of the students in Malaysia still believe that their schools are able to maintain a safe climate for teaching and learning. In addition, there are efforts put in place by the Ministry of Education to convert all schools in Malaysia into 'Effective Schools' where the goal is to attain high academic achievement, systematic evaluation procedures, well-defined rules and discipline to create a safe and conducive environment in schools (Kamaruddin, 2006).

Additionally, the results also showed that there was a significant positive relationship between victims of bullying and science achievement in TIMSS 2015 (mv3) in favour of Malaysian students. In this study, the students claimed they were victims of bullying in terms of other students' spreading lies, sharing embarrassing information and forcing them to do something they did not want to do which supposedly would have a negative impact on student achievement in science. However, the results showed that students' view of themselves as victims of bullying had a positive impact on students' science achievement in TIMSS. This suggests that students in Malaysia, despite being victims of bullying themselves, believe that it does not interfere with their focus on learning and obtaining good achievement in science. This is because precaution has been taken by the Ministry of Education Malaysia to keep the learning environment in schools organised and pleasant by appointing school counsellors and discipline teachers in every school. According to Noriah, Salleh and Abu (2012), all schools in Malaysia have set up counselling services and disciplinary board to overcome disciplinary issues such as 'gengsterisme' and bullying 
and to ensure that students are looked after in school. Moreover, for serious offences, students will be placed in rehabilitation centres (Kamaruddin, 2006). All these are efforts carried out to ensure students do not suffer emotional disorders for long periods of time and that students' academic performance is not affected.

However, based on the structural model comparisons between Malaysia and Japan, it was found that Japan demonstrated a negative significantly stronger path relationship between victims of bullying and school climate (jv5). In other words, the indicators of victims of bullying were found to be contributing negatively to the school climate. This situation seems to be happening more significantly in Japan than in Malaysia. According to Naito and Geilen (2005), bully victims in Japanese schools do not like to declare to teachers that they are being bullied. At the same time, according to Naito and Geilen (2006), Japanese teachers and parents are ignorant the fact that there are bully cases in schools. Hence, it is not surprising those students who victims of bullying will show negative perception of the school climate.

Another interpretation is that bullying in other countries tends to involve two or three students picking on another (Taki, 2001). In Japan however, most cases of bullying involve a larger group of students who may cause psychological and occasionally physical injury on a single victim (Mccrostie, 2017; Taki, 2001). All school activities in Japan such as cleaning, eating lunch and studying are organised in groups (Taki, 2001). Therefore, the victims can hardly defend themselves because they are bullied by a large group. Therefore, the victims in Japan will not feel loved and safe when they are in school.

This study also found that there was no significant difference between Japan and Malaysia in terms of the relationship between attitude towards science and science achievement in TIMSS (mv6/ jv6). This shows that for both Malaysia and Japan, students' attitude towards science impacts their science achievement negatively, and the relationship is stronger for Japan $(\beta=0.350)$ compared to Malaysia $(\beta=0.199)$. Likewise, Ismail et al. (2017) found similar finding; in their study, significant negative relationship was found between attitude towards science and science achievement in TIMSS 2011 among Malaysian students. Thus, it appears that promoting attitude is not enough to promote cognitive achievement in the case of science achievement. The same situation holds true for Japan. Knipprath (2005) stated that the mean score for Japan's science achievement is consistently high but not in the non-cognitive aspect. It appears that Japanese students have a more negative attitude towards science. The consistency of Japan as one of the top internationally ranked countries in education is attributable to the practices in their education system. The Japanese education system is grounded in a deep commitment to students that is concrete, and the system also provides incentives for students to take tough courses and to study hard in school (OECD, 2010). This may have contributed to the high achievement in science in TIMSS among the Japanese; however, it does not reflect the real attitude of Japanese students towards science.

Overall, the non-cognitive factors studied in this study were significantly stronger in most relationships in the tested model for Malaysia compared to Japan. In particular, Malaysia's TIMSS score is positively determined by science teaching practices on attitudes towards science but negatively on science achievement. However, the success of the Japanese in science achievement has to be taken into consideration. According to Kuldas, Hashim and Ismail (2015), students in Malaysia need to enhance their thinking skills especially in critical and creative thinking, counteract risk factors and demonstrate academic resilience in order to compete with other countries that have consistently performed well in international assessments.

The findings of this study relate to non-cognitive factors that occur in classrooms or schools. The success of the Japanese in TIMSS may not be significant when it involves non-cognitive factors in classrooms or schools only. Japan equally emphasises on outdoor learning activities and non-formal learning that can affect their students' cognitive and non-cognitive outcomes. Adult education, non-formal education, out-of-school education and various community-based activities are normally termed as "social education" in the Japanese education system (Arai \& Tokiwa-Fuse, 2013). Social education in Japan is provided by social educational institutions such as community learning centres run by local governments called Kominkans, public libraries and museums. Social education in Japan focuses on teaching young people skills such as self-discipline, collaboration and service. Therefore, all of these off-school activities should be taken into account as a factor that affects the achievement of Japanese students.

\section{SIGNIFICANCE OF THE STUDY}

This study has significance for stakeholders in Malaysia as an effort towards improving science achievement in TIMSS. Stakeholders in Malaysia can take the initiative to emulate non-cognitive aspects that are not only built in classrooms or school. Examples of non-cognitive developments in Japanese educational practices are such as nonformal education, out-of-school education and various community-based activities. These activities not only assist in the development of non-cognitive aspects but also the cognitive ones. In contrast, the stakeholders in Japan can take note of the problems of bullying in their schools, students' view of school climate and sense of belonging to 
the school. Improvements in these aspects can benefit schools and students in Japan not only in terms of science achievement but also in relation to students' mental health and wellbeing.

\section{CONCLUSION}

Based on the assessment of the country moderated model, almost all non-cognitive factors in the model showed significantly different relationships as moderated by the two countries except for the relationship between attitude towards science and science achievement in TIMSS. The findings in this study filled the gap of previous research that did not test the moderating effect of two different countries, and the strength of the relationship between science achievement in TIMSS and its factors based on countries. The current findings of multiple group comparisons add to the existing body of knowledge in that non-cognitive factors that affect science achievement in TIMSS vary depending on school culture and system. Different countries showed different effects of non-cognitive factors on science achievement and this differentiation should be considered in the teaching and learning of science in order to increase the level of achievement.

\section{REFERENCES}

Alias, M., Lashari, T. A., Akasah, Z. A., \& Kesot, M. J. (2014). Translating theory into practice: Integrating the affective and cognitive learning dimensions for effective instruction in engineering education. European Journal of Engineering Education, 39(2), 212-232. https:/ / doi.org/10.1080/03043797.2013.838543

Al-Raqqad, H. K., Al-Bourini, E. S., Al Talahin, F. M., \& Aranki, R. M. E. (2017). The impact of school bullying on students' academic achievement from teachers' point of view. International Education Studies, 10(6), 44. https:/ / doi.org/10.5539/ies.v10n6p44

Anderman, E. M., Sinatra, G. M., \& Gray, D. L. (2012). The challenges of teaching and learning about science in the twenty-first century: Exploring the abilities and constraints of adolescent learners. Studies in Science Education, 48(1), 89-117. https:/ / doi.org/10.1080/03057267.2012.655038

Arai, Y., \& Tokiwa-Fuse, M. (2013). Social Education and Kominkan. Human Right Education in Asia-Pacific (pp. 169195)

Archambault, I., Janosz, M., Fallu, J. S., \& Pagani, L. S. (2009). Student engagement and its relationship with early high school dropout. Journal of adolescence, 32(3), 651-670. https:/ / doi.org/10.1016/j.adolescence.2008.06.007

Barmby, P., Kind, P., \& Jones, K. (2008). Examining changing attitudes in secondary school science. Retrieved from http:/ / doi.org/10.1080/09500690701344966

Bietenbeck, J. C. (2011). Teaching Practices and Student Achievement: Evidence from TIMSS. Master thesis in Economics and Finance at the Centro de Estudios Monetarios y Financieros (CEMFI).

Bofah, E. A. T., \& Hannula, M. S. (2015). TIMSS data in an African comparative perspective: Investigating the factors influencing achievement in mathematics and their psychometric properties. Large-scale Assessments in Education, 3(1), 4. https:/ / doi.org/10.1186/s40536-015-0014-y

Brand, S., Felner, R., Shim, M., Seitsinger, A., \& Dumas, T. (2003). Middle school improvement and reform: Development and validation of a school-level assessment of climate, cultural pluralism, and school safety. Journal of Educational Psychology, 95(3), 570-588. https:/ / doi.org/10.1037/0022-0663.95.3.570

Drent, M., Meelissen, M. R., \& van der Kleij, F. M. (2013). The contribution of TIMSS to the link between school and classroom factors and student achievement. Journal of curriculum studies, 45(2), 198-224. https:/ / doi.org/10.1080/00220272.2012.727872

EP-Nuffic. (2015). Education system Japan: The Japanese education system described and compared with the Dutch system. Retrieved from https://www.nuffic.nl/en/publications/find-a-publication/education-system-japan.pdf

Epstein, J. L. (2008). Improving family and community involvement in secondary schools. Education Digest, 73(6), 9-12.

Epstein, J. L. (2010). School/ family/ community partnerships: Caring for the children we share. Phi Delta Kappan, 92(3), 81-96. https:// doi.org/10.1177/003172171009200326

Fan, X., \& Chen, M. (2001). Parental involvement and students' academic achievement: A meta-analysis. Educational Psychology Review, 13(1), 1-22. https:/ / doi.org/10.1023/A:1009048817385

Fensham, P. J. (2008). Context or culture: can TIMSS and PISA teach us about what determines educational achievement in science? In Internationalisation and globalisation in mathematics and science education (pp. 151172). Springer, Dordrecht. 
Foy, P., \& Joncas, M. (2000). TIMSS Sample Design. In M. O. Martin, K. D. Gregory, \& S. E. Stemler (Eds.), TIMSS 1999 Technical Report (pp. 29-48). International Study Center Lynch School of Education Boston College. Retrieved from http://sling11.bc.edu/timss1999i/pdf/T99_TR.book.pdf\#page=31

Gottfredson, G. D., Gottfredson, D. C., Payne, A. A., \& Gottfredson, N. C. (2005). School climate predictors of school disorder: Results from a national study of delinquency prevention in schools. Journal of Research, 42(4), 412444. https:/ / doi.org/10.1177/0022427804271931

Gregory, A., Skiba, R. J., \& Noguera, P. A. (2010). The achievement gap and the discipline gap two sides of the same coin? Educational Researcher, 39(1), 59-68. https:// doi.org/10.3102/0013189X09357621

Halim, L., \& Meerah, S. M. M. (2002). Science trainee teachers' pedagogical content knowledge and its influence on physics teaching. Research in Science $\mathcal{E}$ Technological Education, 20(2), 215-225. https:/ / doi.org/10.1080/0263514022000030462

Halim, L., Abdullah, S. I. S. S., \& Meerah, T. S. M. (2014). Students' perceptions of their science teachers' pedagogical content knowledge. Journal of Science Education and Technology, 23(2), 227-237. https:/ / doi.org/10.1007/s10956-013-9484-2

Ibrahim, A. (2015). Science education in Malaysia needs urgent overhaul. New Straits Times July, 27. Retrieved from https://www.nst.com.my/news/2015/09/science-education-malaysia-needs-urgent-overhaul

Ice, C. L., \& Hoover-Dempsey, K. V. (2011). Linking parental motivations for involvement and student proximal achievement outcomes in home schooling and public schooling settings. Education and Urban Society, 43(3), 339-369. https:/ / doi.org/10.1177/0013124510380418

Ingels, S. J., Burns, L. J., Chen, X., Cataldi, E. F., \& Charleston, S. (2005). A profile of the American high school sophomore in 2002: Initial results from the base year of the Educational Longitudinal Study of 2002.

International Association for the Evaluation of Educational Achievement [IEA]. (2017). Supplement 1: International Version of the TIMSS 2015 Context Questionnaires Timss 2015 User Guide for The International Database. Boston College.

Ismail, M. E., Samsudin, M. A., Amin, N. F. M., Kamarudin, N., Daud, K. A. M., \& Halim, L. (2018). Contributing factors to science achievement in TIMSS Malaysia: Direct model and indirect model. International Journal of Engineering \& Technology, 7(4.30), 423-428.

Ismail, M. E., Samsudin, M. A., Ismail, A., \& Halim, L. (2017). Factors related to science achievement in TIMSS Malaysia: A Confirmatory factors analysis. Man in India Serials Publications, 97(2), 873-888.

Itoh, M., \& Phouttha, K. (2005). A Comparison Study of Education Systems between the Laos and Japan for the Improvement of Future Education. Research Bulletin of Humanities and Social Sciences, 20, 9-22.

Jacobs, J. E., \& Eccles, J. S. (2000). Parents, task values, and real-life achievement-related choices. In C. Sansone \& J. M. Harackiewicz (Eds.), Intrinsic and extrinsic motivation: The search for optimal motivation and performance (pp. 405-439). San Diego, CA: Academic Press. https:/ / doi.org/10.1016/B978-012619070-0/50036-2

Jeynes, W. H. (2003). A meta-analysis: The effects of parental involvement of minority children's academic achievement. Education and Urban Society, 35(2), 202-218. https:/ / doi.org/10.1177/0013124502239392

Jeynes, W. H. (2007). The relationship between parental involvement and urban secondary school student academic achievement. A meta-analysis. Urban Education, 42(1), 82-110. https:/ / doi.org/10.1177/0042085906293818

Johnston, M. P. (2014). Secondary Data Analysis: A Method of which the Time Has Come. Qualitative and Quantitative Methods in Libraries (QQML), 3, 619-626.

Kamaruddin, K. (2006). Management of effective schools in Malaysia: Issues and challenges. Retrieved from http:/ / www.jgbm.org/page/21\%20\%20Kamaruddin.pdf

Kawasaki, K. (1996). The concepts of science in Japanese and Western education. Science E Education, 5(1), 1-20.

Knipprath, H. (2005). Quality and equity: Japanese education in perspective. Antwerpen: Garant Publishers.

Kuldas, S., Hashim, S., \& Ismail, H. N. (2015). Malaysian adolescent students' needs for enhancing thinking skills, counteracting risk factors and demonstrating academic resilience. International journal of adolescence and youth, 20(1), 32-47. https:/ / doi.org/10.1080/02673843.2014.973890

Lay, Y., \& Chandrasegaran, C. (2016). The predictive effects of motivation toward learning science on TIMSS grade 8 students' science achievement: A comparative study between Malaysia and Singapore. Eurasia Journal of Mathematics, Science and Technology Education, 12(12), 2949-2959. https://doi.org/10.12973/eurasia.2016.02315a

Ma, X. (2003). Sense of Belonging to School: Can Schools Make a Difference? The Journal of Educational Research, 96(6), 340-349. https:/ / doi.org/10.1080/00220670309596617 
Maliki, A. E., Asogwara, C. C., \& Ibu, J. E. (2009). Bullying and its effects on the academic performance of secondary school students in Nigeria. J Hum Ecol, 25(3), 209-213. https:/ / doi.org/10.1080/09709274.2009.11906157

Martin, M. O., Mullis, I. V. S., Foy, P., \& Hooper, M. (2017). TIMSS 2015 International Results in Science: Eighth Grade Science. Boston: TIMSS \& PIRLS International Study Center.

Maxwell, S., Reynolds, K. J., Lee, E, Subasic, E., \& Bromhead, D. (2017). The impact of school climate and school identification on academic achievement: multilevel modeling with student and teacher data. Frontiers in Psychology, 8(article 2069), 1-21. https:/ / doi.org/10.3389/fpsyg.2017.02069

Megumi, L. (2017). Bullying keeps youth suicides high in Japan. Retrieved from https:/ / www.stuff.co.nz/world/asia/91911106/bullying-keeps-youth-suicides-high-in-japan

Ministry of Education Malaysia. (2003). Integrated curriculum for secondary schools, curriculum specifications for year 2 science. Putrajaya: Curriculum Development Centre.

Ministry of Education Malaysia. (2005). Integrated Curriculum for Secondary Schools: Curriculum specifications Science Form 4. Putrajaya: Curriculum Development Centre.

Ministry of Education Malaysia. (2016). TIMSS 2015 Report- Trends in International Mathematics and Science Study. Putrajaya: Education Policy Planning and Research Division.

Ministry of Education, Culture, Sports, Science, and Technology. (2008). Guidelines for teaching junior high school (English version). Retrieved from http://www.mext.go.jp/a_menu/shotou/newcs/youryou/eiyaku/1298356.htm

Mohtar, L. E., Halim, L. \& Iksan, Z. H. (2016). Cognitive, Affective and Students' Achievement in Physics: A Hypothetical Model for Structural Equation Modeling Testing. 4th International Conference on ASEAN Comparative Education Research Network (ACERN 2016). Padang, West Sumatera. 30-1 Dec 2016 (pp. 20802091)

Mullis, I. V. S., Martin, M. O., Goh, S., \& Cotter, K. (Eds.) (2016). TIMSS 2015 Encyclopedia: Education Policy and Curriculum in Mathematics and Science. Retrieved from Boston College, TIMSS \& PIRLS International Study Center website http:/ / timssandpirls.bc.edu/timss2015/encyclopedia/

Naito, T., \& Gielen, U. P. (2005). Bullying and Ijime in Japanese schools. In Violence in Schools. 169-190. Springer, Boston, MA. https://doi.org/10.1007/0-387-28811-2_9

Norfarah, N., Mohd, A. S., \& Ahmad, N. M. Z. (2015). Gender moderated model of innovation orientation among Malaysia undergraduates. The Social Sciences, 10(7), 1645-1653.

Noriah, M. I., Salleh, A. \& Abu, Y. A. B. (2012). Counseling professional ethics from viewpoint of counsellor educators. Journal of Educational Psychology E Counseling, 5, 71-80.

Organisation for Economic Co-operation and Development [OECD]. (2010). Japan: A Story of Sustained Excellence. Retrieved from https://www.oecd.org/japan/46581091.pdf

Osborne, J., Simon, S., \& Collins, S. (2003). Attitudes towards science: A review of the literature and its implications. International Journal of Science Education, 25(9), 1049-1079. http:/ / doi.org/10.1080/0950069032000032199

Pehlivan, H., \& Koseoglu, P. (2011). The reliability and validity study of the attitude scale for physics course. Procedia Social and Behavioral Sciences, 15, 3338-3341. https:/ / doi.org/10.1016/j.sbspro.2011.04.296

Planty, M., DeVoe, J., Owings, J., \& Chandler, K. (2005). An Examination of the Conditions of School Facilities Attended by 10th-Grade Students in 2002. ED TAB. NCES 2006-302. National Center for Education Statistics.

Prokop, P., Tunnicliffe, S. D., Kubiatko, M., Hornáčková, A., \& Usak, M. (2011). The role of teacher in students' attitudes to and achievement in Palaeontology. Energy EducSciTechnol Part B, 3(1), 29-45.

Scheerens, J. (2008). Eenoverzichtsstudienaar school-eninstructie-effectiviteit [Review of research on school and instructional effectiveness]. Enschede: University of Twente, Department of Educational Organisation and Management.

She, H. C., \& Fisher, D. (2002). Teacher Communication Behaviour and its Association with Students' Cognitive and Attitudinal Outcomes in Science in Taiwan. Journal of Research in Science Teaching, 39(1), 63-78. https://doi.org/10.1002/tea.10009

Sheldrake, R., Mujtaba, T., \& Reiss, M. J. (2017). Science teaching and students' attitudes and aspirations: The importance of conveying the applications and relevance of science. International Journal of Educational Research, 85, 167-183. https:/ / doi.org/10.1016/j.ijer.2017.08.002

Shi, W. Z., He, X., Wang, Y., Fan, Z. G., \& Guo, L. (2016). PISA and TIMSS Science Score, Which Clock is More Accurate to Indicate National Science and Technology Competitiveness? Eurasia Journal of Mathematics, Science \& Technology Education, 12(4), 965-974. 
Shulman, B. (2003). Why are attitudes so hard to change? Psychology in action. Retrieved from https:/ / www.psychologyinaction.org/psychology-in-action-1/2013/11/28/why-are-attitudes-so-hard-tochange

Son M. J. (2009). A Study of Korean students' creativity in science using structural equation modeling (Doctoral Thesis), Universiti Arizona, United State of America.

Ssekamanya, S. A., Badzis, M., Ismail, K., \& Abduludin, D. S. B. (2016). Predictors of school safety awareness among Malaysian primary school teachers. European Journal of Social Sciences Education and Research, 6(1), 88-93. https://doi.org/10.26417/ejser.v6i1.p88-93

Suzuki, A. (2007). Attitudes of Japanese students in relation to school biology. University of Glasgow: Master of Science Thesis.

Taki, M. (2001). Japanese School Bullying: Ijime: A survey analysis and an intervention program in school. National Institute for Educational Policy Research of Japan communication at Queen's University. Canada.

Thomson, S., Wernert, N., O'Grady, E., \& Rodrigues, S. (2017). TIMSS 2015: Reporting Australia's Results. Camberwell, Victoria: Australian Council for Educational Research Ltd.

Togari, T., Sato, M., Yagasaki, Y., \& Otemori, R. (2011). The development of Japanese 13-item version of psychological sense of school membership scale for Japanese urban high school students. School Health, 7, 62-72.

Topcu, M. S., Erbilgin, E., \& Arikan, S. (2016). Factors Predicting Turkish and Korean Students' Science and Mathematics Achievement in TIMSS 2011. Eurasia Journal of Mathematics, Science E Technology Education, 12(7).

Veloo, A., Rahimah Nor, \& Rozalina, K. (2015). Attitude towards physics and additional mathematics achievement towards physics achievement. International Education Studies, 8(3), 35-43. https:/ / doi.org/10.5539/ies.v8n3p35

Wang, M. T., \& Degol, J. L. (2015). School climate: a review of the construct, measurement, and impact on student outcomes. J. Educ. Psychol. Rev., 28, 1-38. https:/ / doi.org/10.1007/s10648-015-9319-1

\section{http://www.ejmste.com}

